\title{
Indonesian EFL Learners' Critical Thinking in Reading: Bridging the Gap between Declarative, Procedural and Conditional Knowledge
}

\author{
Concilianus Laos Mbato \\ English Education Masters Program, Sanata Dharma University, Indonesia \\ Email:cons@usd.ac.id
}

\begin{abstract}
Critical thinking is explicitly mentioned in many school and university curricula around the world including in the Indonesian education curriculum but it is rarely promoted inside the classrooms. Lack of agreement on its definition and clarity of instruction in the curriculum, the unfavourable culture and the teacher-centred teaching arguably prevent critical thinking to grow. Therefore, more research needs to be undertaken on students' understanding of and engagement in critical thinking in reading. To fill the gap, this study was conducted, which aimed to investigate Indonesian learners' critical thinking in reading. One research question was postulated, i.e., How critical are Indonesian EFL learners' thinking in reading? To answer the question, a mixed method approach was undertaken. The participants of this study were 55 semester four students enrolled in two classes of Critical Reading and Writing II (CRW2) of the English Education Study Program, Sanata Dharma University, Yogyakarta in the even semester of 2014. The instruments employed were a Likert-scale questionnaire and students' reflections. Results from both quantitative and qualitative data analyses suggest that most of the students had sufficient declarative knowledge of critical thinking in reading. However, their procedural and conditional knowledge about critical thinking in reading were insufficient. Overall, students indicated some level of critical thinking in reading, but to become critical, they need to be in a learning environment where their critical thinking in reading could be regularly and intensively nurtured. The findings of the research are expected to inform English teachers, lecturers and researchers in Indonesia and other parts of the world about the importance of designing and carrying out the teaching learning processes that can enhance learners' declarative, procedural and conditional knowledge about critical thinking in reading.
\end{abstract}

Keywords: critical thinking; reading; metacognitive strategies; declarative; procedural; conditional

\section{INTRODUCTION}

Critical thinking is an important $21^{\text {st }}$ century learning skill that needs to be taught and learnt in the academic life of the students (Yang, Gamble, Hung \& Lin, 2013). To be successful academically, students not only need to think but to think critically. In order to accomplish the mission, they need support from academic staff, who themselves are well versed in critical thinking both conceptually and practically particularly when it comes to reading. However, Paul (2005) warned that many faculty members lack a proper understanding of critical thinking and therefore believe that they have taught them while in fact they have not.

Although critical thinking has been included in many school and university curricula around the world, its definition and elements are not as clear-cut as its popularity (Kuhn, 1999; Stapleton, 2011). Ilyas (2016) argues that critical thinking is a common term but has been defined and understood differently by different 
authors. Cottrell (2005, p. 5) conceptualizes critical thinking as "a complex process of deliberation which involves a wide range of skills and attitudes" while Paul (1990, p. 32) sees critical thinking as "the art of thinking about your thinking".

Though using slightly different terms, these authors (Walters, 1990; Bailin, Roland, Coombs, \& Daniels, 1999; Cottrell 2005) suggest similar elements and requirements of critical thinking, i.e., the thinker's knowledge, skills and attitudes in dealing with arguments. To be able to test an argument, the person needs to use his/her background knowledge, evaluate the evidence wholly, scrutinise own and the writer's underlying beliefs, examine the reasoning and discourse markers, as well as make a logical conclusion. Despite the important role critical thinking plays in students' learning and life success in the $21^{\text {st }}$ century, lack of agreement on its definition and elements may hinder the teaching and application of critical thinking in the classrooms.

Wallace (2003) states a commonly accepted definition of critical thinking in reading as "the ability to critique the logic of texts, to note inconsistencies and lack of clarity" (p. 27). While critical reading is an important skill in reading, he points out the absence of critical reading in most language classrooms and encourages learners to develop diverse critical tools and prioritises meaning in reading (p. 3). Similarly, Cottrell (2005, p. 13) defines critical thinking in reading as the readers' knowledge, skills and attitudes in reading.

In order for learners to understand and develop skills of critical thinking in reading, they need to possess declarative, procedural and conditional knowledge of critical thinking in reading (Brown, 1987). Paul and Elder (2008) provide eight criteria which need to be met when one applies critical thinking in reading, i.e., the abilities to understand and determine the article's purpose, the key question, the most important information and ideas in the article, the key conclusions, the author's line of reasoning, the main assumption(s) underlying the author's thinking, the consequences upon accepting or rejecting the author's line of reasoning, and the author's main point(s) of view (p. 13). Cottrell (2005, p. 13) provides 25 elements of critical thinking in reading and writing covering knowledge, skills and attitudes such as knowledge about line of reasoning and argument patterns, skill in determining the key ideas, and feeling good at criticizing someone's writing.

All the authors above suggest similar elements of critical thinking in reading, yet there is no consensus as to what critical thinking in reading consists of. Kuhn (1999) laments about the lack of literature on critical thinking that is readily available to teachers teaching reading. Regardless of the absence of the concepts and how it has to be implemented in the classrooms, many governments around the world include critical thinking in their education curriculum (cf. Wallace \& Poulsten, 2005; Fisher 2008; Hove, 2011; Ilyas, 2016).

One way of thinking and explaining about critical thinking is through the lense of metacognitive strategies. Metacognitive strategies are understood as the readers' knowledge and skills to take control of their learning by planning, monitoring and evaluating (Chamot \& O'Malley, 1994; Ellis, 1994; Chamot; Barnhardt, El-Dinary, \& Robbins, 1999). Metacognition, critical thinking and text understanding in reading are inseparable (Kuhn, 1999; Griffith \& Ruan, 2005; Downing, Kwong, Chan, Lam, \& Downing, 2008; Park, 2011; Fisher \& Frey, 2015). When learners think before reading, while reading, and after reading, they are engaged in metacognition. To ease understanding and discussion, critical thinking in reading can be grouped into the planning, the monitoring and the evaluation phases, and explained using the three types of knowledge (cf. Brown, 1987; Kuhn, 1999; Weinstein, Husman, \& Dierking, 2000), that is, declarative (knowing what), procedural (knowing how) and conditional knowledge (knowing when and why).

The Indonesian government places critical thinking as one of the most important skills to be taught and learnt at schools, and universities, as evidenced in the 2013 school curriculum and in the issue of 2010 Decree No. 17 about Indonesian education system and its implementation. However, the implementation of critical thinking inside the classrooms in Indonesia is lacking. Part of the problem in the teaching of critical thinking in Indonesia is a lack of clarity of instruction in the curriculum about what critical thinking is, and the unfavourable culture as well as the teaching learning processes inside the classrooms for students' critical thinking to grow (Lengkanawati, 2004; Lamb, 2004; Marcellino, 2008; Rachmajanti, 2017; Indah \& Kusuma, 2016; Indah, 2017).

In the light of the above review, it is clear that more research needs to be conducted on university's students' understanding and engagement in critical thinking in reading. This study was carried out to explore Indonesian students' critical thinking in reading. I was motivated to find out if and whether the students possessed declarative, procedural and conditional knowledge about critical thinking in reading. In conducting the study, I used the components of critical thinking in reading by Cottrel (2005; see appendix 1). These components were grouped using the three metacognitive strategies (Chamot 
\& O'Malley, 1994) and analyzed using the declarative, procedural, or conditional knowledge types (Brown, 1987; Weinstein, Husman, \& Dierking, 2000).

This study adopted a mixed method approach combining both quantitative and qualitative research (see e.g., Neuman, 2006; Onwuegbuzie, Johnson \& Collins, 2009; Creswell, 2012) to explore the students' understanding and use of critical thinking in reading. The participants of this study were 55 semester four students enrolled in two classes of Critical Reading and Writing II (CRW2) of the English Education Study Program, Sanata Dharma University in the even semester of 2014. To collect the quantitative and qualitative data, a questionnaire and students' reflection about their critical thinking in reading were used.

The Likert-typed questionnaire consisting of three options, i.e., Disagree, Undecided, and Agree were used to collect quantitative data. The data was analysed descriptively focusing on finding the percentages of the students' answers to the 23 self-evaluation statements of critical thinking (based on Cottrell, 2005, p. 13). Evaluation statements 18 (on ability to present an argument clearly) and 25 (on ability to spot ambiguous language in research papers) were dropped since the former was related to writing and the latter to research papers, not argumentative reading passages. These elements were then grouped under the planning, monitoring and evaluation strategies. Qualitative data generated from the students' reflective answers to the four WH-Questions were analysed focusing on the themes pertaining to their critical thinking in reading. Both data were then analysed focusing on the students' critical thinking in reading (Cottrell, 2005), metacognitive strategies (based on Chamot \& O'Malley, 1994; Chamot; Barnhardt, El-Dinary, \& Robbins, 1999), and three types of knowledge (Brown, 1987; Weinstein, Husman, \& Dierking, 2000).

\section{RESULTS \\ Quantitative data analysis}

Quantitative data analysis focuses on the three metacognitive strategies that underpinned the students' critical thinking in reading, i.e., planning, monitoring and evaluation, and the three types of knowledge. There were twenty three (23) statements asking students about their critical thinking in reading. The statements on strategies are grouped into two, i.e.,: 1) planning, monitoring, and evaluation strategies of critical thinking in reading; and 2) planning, monitoring and evaluation of feelings in critical reading.

\section{Planning, Monitoring and Evaluation Strategies of Critical Thinking in Reading}

The students' responses to seventeen (17) statements about planning, monitoring and evaluation about critical thinking in reading are indicated in Table 1.

Data about the students' responses to the planning, monitoring and evaluation statements about critical thinking in reading is further presented in the following chart.

Figure 1. The students' responses to seventeen statements about planning, monitoring and evaluation about critical thinking in reading.

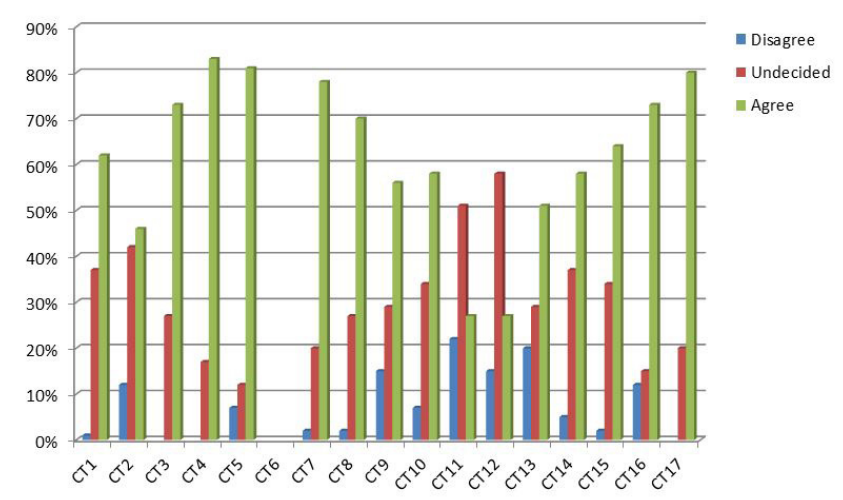

Both Table 1 and Figure 1 depict the students' responses to the planning, monitoring and evaluation statements of critical thinking in reading simultaneously. The students' responses were grouped into three, i.e., the highest, moderate and the lowest agreement to the statements. The highest percentage was indicated by students' responses to statement CT4 with $83 \%$ of the students admitting that they were able to find facts, experiences and data used by the author to support his/ her conclusions. Eighty one percent (CT5) agreed that they could identify discourse tools, which were used to mark idea development, followed by eighty percent who acknowledged that they could identify the main conclusions in the article (CT17). Seventy eight percent admitted being able to find key questions in the article (CT7). The agreement to the statements the ability to analyse arguments used in the reading (CT3) was $73 \%$, and the ability to evaluate references used in the reading (CT16) was $73 \%$. Seventy percent of the students indicated that they were able to identify unfair techniques used by the writer to persuade the readers (CT8), and sixty four percent agreed that they were able to identify the unclear arguments in the reading (CT15). 
Table 1. The students' responses to the planning, monitoring and evaluation statements of critical thinking in reading

\begin{tabular}{|c|c|c|c|c|}
\hline No. & Statements & Disagree & Undecided & Agree \\
\hline CT1 & I can critique the logic of the text & $1 \%$ & $37 \%$ & $62 \%$ \\
\hline $\mathrm{CT} 2$ & I remain focused on the exact requirements of a reading activity & $12 \%$ & $42 \%$ & $46 \%$ \\
\hline CT3 & I can analyse the structure of an argument & & $27 \%$ & $73 \%$ \\
\hline CT4 & $\begin{array}{l}\text { I can figure out the facts, experiences, data the author is using to } \\
\text { support her/his conclusions }\end{array}$ & & $17 \%$ & $83 \%$ \\
\hline CT5 & $\begin{array}{l}\text { I recognize the signals used to indicate stages of an argument in the } \\
\text { reading }\end{array}$ & $7 \%$ & $12 \%$ & $81 \%$ \\
\hline CT6 & I can separate key points from other material & $10 \%$ & $42 \%$ & $48 \%$ \\
\hline CT7 & I can find key problems (key question) in the reading & $2 \%$ & $20 \%$ & $78 \%$ \\
\hline CT8 & I can identify unfair techniques used to persuade readers & $2 \%$ & $27 \%$ & $70 \%$ \\
\hline CT9 & $\begin{array}{l}\text { I can figure out the main assumption(s) underlying the author's thinking } \\
\text { ( that may be taken for granted) in the reading }\end{array}$ & $15 \%$ & $29 \%$ & $56 \%$ \\
\hline CT10 & I can evaluate the evidence in the reading to support a point of view & $7 \%$ & $34 \%$ & $58 \%$ \\
\hline CT11 & I pay attention to small details in the reading & $22 \%$ & $51 \%$ & $27 \%$ \\
\hline CT12 & I can weigh up different points of view in the reading fairly & $15 \%$ & $58 \%$ & $27 \%$ \\
\hline CT13 & $\begin{array}{l}\text { I do research to find out more about something related to the reading to } \\
\text { strengthen my understanding. }\end{array}$ & $20 \%$ & $29 \%$ & $51 \%$ \\
\hline CT14 & I can spot inconsistencies in an argument easily. & $5 \%$ & $37 \%$ & $58 \%$ \\
\hline CT15 & I can identify the unclear arguments used in the reading. & $2 \%$ & $34 \%$ & $64 \%$ \\
\hline CT16 & I can evaluate the sources of data used as references in the reading. & $12 \%$ & $15 \%$ & $73 \%$ \\
\hline CT17 & $\begin{array}{l}\text { I can identify the key conclusions the author comes to and presents in } \\
\text { the article. }\end{array}$ & & $20 \%$ & $80 \%$ \\
\hline
\end{tabular}

Slightly more than half of the respondents showed moderate agreement to the statements with $56 \%$ (CT9) indicated that they could figure out the main assumption(s) underlying the author's thinking in the reading, 58\% (CT10) showed that they could evaluate the evidence in the reading to support a point of view and 58\% agreed that they were able to show inconsistencies in the reading (CT14). Some responses indicated low agreements with the statements (below 50\%). Forty eight percent (48\%/ CT6) of the respondents agreed that they could separate key points from other material. Forty six percent of the students $(46 \% / \mathrm{CT} 2)$ showed that they were able to concentrate on the reading. The lowest percentage of the agreement responses occurred to statements CT11 and CT12 where $22 \%$ of the students agreed that usually paid attention to the details (CT11) and that they considered various viewpoints in the reading (CT12). Statements CT2, CT11 and CT12 need further explanations due to the high proportion of the students who were undecided in relation to the statements (CT2/42\%; CT11/51\%; CT12/58\%). The responses may suggest that maintaining focus on the reading (CT2), paying attention to small details (CT11) and weighing up different points of view in the reading (CT12) was a challenging task for students which requires more training for them to be skilled.

Overall, the majority of the students indicated, through their responses, that they implemented some monitoring, evaluation and planning strategies. However, some students were not yet able to fully implement these critical thinking strategies in reading.

\section{Planning, Monitoring and Evaluation of Feelings in Critical Reading}

The students were asked six statements pertaining to the use of the planning, monitoring and evaluation of feelings in critical reading. Their responses are presented in Table 2 . 
Table 2. The students' responses to the use of the planning, monitoring and evaluation of feelings in critical reading

\begin{tabular}{|c|c|c|c|c|}
\hline No. & Statement & Disagree & Undecided & Agree \\
\hline CT18 & $\begin{array}{c}\text { I feel comfortable in pointing out the weakness of an expert's work in } \\
\text { reading }\end{array}$ & $12 \%$ & $39 \%$ & $49 \%$ \\
\hline CT19 & I can offer criticism to the reading without feeling bad & $7 \%$ & $38 \%$ & $55 \%$ \\
\hline CT20 & $\begin{array}{c}\text { I am aware of my current beliefs' prejudice on fair consideration of an } \\
\text { issue }\end{array}$ & $15 \%$ & $12 \%$ & $73 \%$ \\
\hline CT21 & I am patient in identifying the line of reasoning in an argument & $24 \%$ & $34 \%$ & $42 \%$ \\
\hline CT22 & I am patient in going over the facts in order to reach an accurate view & $15 \%$ & $49 \%$ & $36 \%$ \\
\hline CT23 & $\begin{array}{c}\text { I realise how my upbringing might prejudice fair consideration of an } \\
\text { issue in the reading }\end{array}$ & $19 \%$ & $42 \%$ & $39 \%$ \\
\hline
\end{tabular}

To facilitate the readers' understanding about the students' responses to the use of the planning, monitoring and evaluation of feelings in critical reading, the following chart is presented.

Figure 2. The students' responses to the use of the planning, monitoring and evaluation of feelings in critical reading

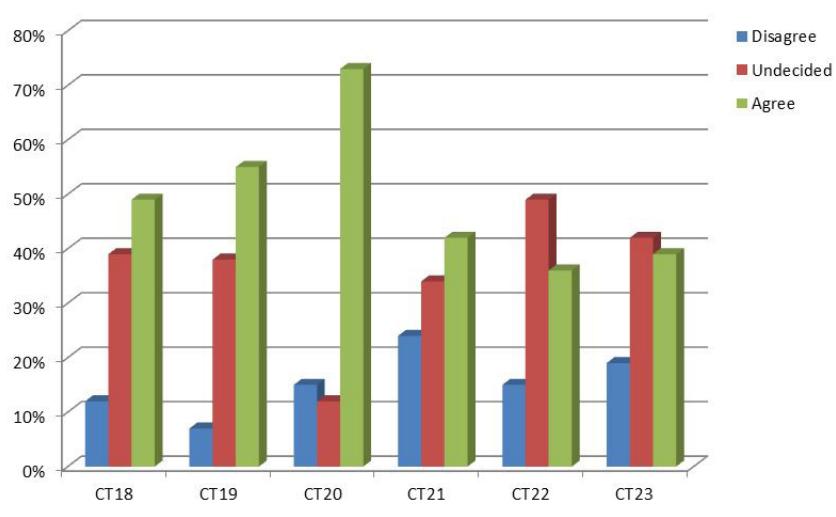

As indicated above (Table 2 and Figure 2), six statements were constructed to investigate students' emotional responses in reading. Most of the students indicated low agreement to all the statements except to statements CT20 and CT 19. Students' responses indicated that more than half agreed to statements CT20 (73\%), i.e., an awareness that their beliefs can prejudice them against an issue, and CT19 (55\%), i.e., the ability to critique a reading without making them become a bad person. The other four responses indicated low agreement to the statements with statement CT18 on whether they felt comfortable in pointing out the potential weaknesses of the works by experts (49\%), statement CT21 on their patience in identifying the reasoning used in reading
(42\%), statement CT23 on how they were reared may make them prejudice against an issue in reading (39\%), and statement CT22 on their patience in reviewing facts in order to reach a correct understanding of the reading $(36 \%)$.

The students' answers to the statements on their ability to plan, monitor and evaluate their feelings in reading suggest that the majority of them were not able to implement critical thinking in reading due to an inability to plan, monitor and evaluate their feelings.

Overall, the quantitative data analysis suggest that most of the students were not yet able to consistently implement critical thinking in reading although there were indications of the planning, monitoring and evaluation strategies being implemented sporadically.

\section{Qualitative data analysis}

Qualitative data focused on inviting students to reflect on four critical thinking questions in reading, i.e., : 1) what critical thinking techniques do you use in reading?; 2) what hinders you from thinking critically in reading?; 3) what do you do when you find difficulties in reading?; and 4 ) how critical are you in reading? These four questions were used to reveal the students' critical thinking in reading, and were analysed separately.

\section{What critical thinking techniques do you use in reading?}

Students mentioned eleven reading techniques they often used in reading. These strategies can be grouped into the planning, monitoring and evaluation strategies when seen under the lens of the metacognitive strategies.

Some students indicated evidence of the use of the planning strategies in the form activating one's background knowledge with regard to the issue (for 
example, S19, S35 and S37). Other strategies were a combination of the implementation of the planning, monitoring and evaluation strategies although students did not mention the metacognitive strategies per se explicitly. They were skimming (S12, S16, S29), scanning (S07), outlining, summarising in own words and identifying main ideas (S09), reading intensively and staying focused (S03, S07, S26, S27, S28, S29 and S38), following the explanations in the paragraph carefully and in detail (S25 and S39), reading again while paying attention on paragraphs (S10 and S40), taking important points and then making concept maps (S08), paying careful attention to the explanations and details given by the writer (S13), identifying the key message in the sentence/topic (S14), connecting old and new information when reading and being curious about something (S11) focusing on the organisation of the text and the writer's point of view (SO4 and S05), underlining as this technique keeps the student focused on the reading (S15), finding the main ideas, evidence, arguments, and then draw conclusions based on the evidence (S22, S24 and S36), focusing on the topic sentence and supporting sentences in each paragraph (S20), note-making in every paragraph (S23), reading aneasy-to understand text (S18). Other students mentioned interest in the topic and the desire as well as the mood in reading were the strategies they used (for example, S09).

Overall students did reveal their understanding of the importance of employing techniques in reading. However these strategies were not fully grasped by each individual student. They tended to use similar and familiar strategies to all reading texts. The second question invited students to reflect on the factors inhibiting their critical thinking in reading.

\section{What hinders you from thinking critically in reading?}

At least eight factors were cited by students as inhibiting their critical thinking in reading. The first cause was inability to maintain concentration in reading. Student S29 admitted 'too often I can't focus on the passage making me lose track of the key issues there'. Other students, such as S14, s20, S25, and S38, also acknowledged being unable to stay focused on the reading. One student (S08) added 'I can't focus my attention in reading/in reading something again because I feel bored easily'. Lack of interest in the topic was cited by S03, S04, S07, S09, S21 and $\mathrm{S} 40$ as inhibiting their critical thinking in reading. Insufficient knowledge of the topic was another cause of students' inability to implement critical thinking in reading (as admitted by S05, S28 and S44). Students such as S05 and S33 mentioned reluctance to critique someone's idea as the major cause, which inhibited their critical thinking in reading. Other students, for example S05, S11, S12, S13, S15, and S29, mentioned that they were too lazy and not motivated to think hard. Lack of patience was also a dominant factor influencing students' critical thinking as admitted by S07. The next factor was the text difficulty. Students such as S10, S16, S17, S29, and $\mathrm{S} 49$ added that the difficulty could be related to the vocabulary, ideas, or the writing style used. The last factor influencing students' application of critical thinking in reading was the unsupportive learning environment. The interruption could come in the form of a friend asking to hang around (S37), the wrong time and place of the reading activity (S35 and S41).

The students' answers demonstrate their understanding of the many factors that may impede their critical thinking and how these may negatively impact on their reading. The third question assisted students to reflect on the problem-solving strategies they undertook when they faced difficulties in critical reading.

\section{What do you do when you find difficulties in critical reading?}

Six strategies were undertaken by students when encountering critical reading difficulties. The first strategy was reading again until they understood the message in the text. Many students admitted adopting this fix-up strategy (S03, S04, S05, S07, S08, S12, S16, 17, S18,S19, S20, $\mathrm{S} 21, \mathrm{~S} 25, \mathrm{~S} 30, \mathrm{~S} 31, \mathrm{~S} 46, \mathrm{~S} 50, \mathrm{~S} 51$ and S52). The second most common strategy was seeking help from friends or from other resources in the internet (S10, S11, S12, S13, S22, S29, S36 S41 and S48). Vocabulary seemed to be the source of difficulty for many students' understanding of the text. This was evident by students S26, S28, S30 and S40, who admitted finding the meaning of difficult words as the strategy they used in when encountering difficulties in reading. Rather than continuing working on the text that presented difficulty, students S24, S32 and S37 would stop reading, do something else and get back to it afresh.

In general many students came up with some strategies when encountering difficulties in reading. However, they would need to be prompted to reflect on whether these strategies were effective. The last question asked students to evaluate their critical thinking in reading.

\section{How critical are you in reading?}

Four themes appeared when asked whether they were critical in reading. Most of the students admitted that they were not so critical in reading. Some students also 
included some reasons why they were not critical. S04, $\mathrm{S} 12$, S29, and S37 said that they were still in the process of learning to be critical. Student S04 said that she was not so critical particularly when she did not have any experience related to the issue in the passage. Lack of familiarity with the topic of the reading influenced students' critical thinking in reading such as $\mathrm{S} 07, \mathrm{~S} 13$, S14, S16, S31, 33, 44 and 53. Other students were not critical because of various reasons such as the tendency to agree with the shared/common opinions (S18), a focus on understanding the words rather than the message in the passage (S20), disliking reading (S32), not being careful in reading and understanding the passage (S26), and reading without thinking about it critically (S54).

Some students admitted that they were quite critical. They included reasons such as S10 who said that she was able to express her opinions to friends and critique other peoples' opinions, i.e., not accepting them blindly. S22 mentioned that she was quite critical but still unable to give clear and critical comments. S23 was quite critical to new things but not so critical to things which agreed with his understanding (beliefs). S29 had the habit of finding grammatical mistakes in the passage and commenting on some details. Other students acknowledged that they did not know whether they were critical or not. S09 said that she could not measure how critical she was. S21 said that "we could not evaluate ourselves". S55 was not sure since all this time she read the text without thinking critically.

From all the students' answers to all the questions, it seemed that they had a sufficient understanding of the concept and importance of critical thinking in reading. They also employed certain strategies in reading demonstrating their ability to plan, monitor, and evaluate strategies in reading. However, many students also admitted that they were not yet that critical in reading.

Therefore, students need to be introduced to various kinds of critical thinking strategies in reading. They should also be given ample opportunity to practice these strategies so that they could become more skilled in thinking and reading and were able to decide when to implement a strategy as required by a text. In other words, they should be taught the declarative, procedural and conditional knowledge of critical thinking in reading.

\section{DISCUSSION}

Results from both the quantitative and qualitative data analyses indicate that the students' understanding of and ability to implement critical thinking in reading were sporadic and not comprehensive in that they were able to implement some strategies but not others.

The students' ability to implement the planning, monitoring and evaluation strategies of critical thinking in reading was partial. The majority of them indicated, through their responses, that they implemented some planning, monitoring and evaluation strategies but not others. They also admitted that they were yet confident in implementing these critical thinking strategies in reading. From the the analysis, it was necessary that the students be introduced to knowledge of cognition and regulation of cognition in order to enhance their chances of success in using critical thinking. Knowledge of cognition comprises declarative (knowing what), procedural (knowing how) and conditional knowledge (knowing when and why), while regulation of cognition constitutes one's ability to plan, monitor and evaluate learning (Brown, 1987). Possessing sufficient knowledge of the strategies and being able to use them appropriately as required by the reading as well as the ability to plan, monior and evaluate these strategies will enhance their critical thinking in reading. Further practice on these strategies is needed for students to take ownership of them. For this to happen, teachers need to change their traditional approach in teaching as reminded by Mbato (2013, p. 166):

In the short term, the traditional approach to teaching may stifle learners' creativity, sense of independence and ownership of learning, and therefore debilitate their engagement in English language learning. In the long run, it may discourage the growth of selfregulated learning and lead to underachievement.

Students' ability to regulate their critical thinking in reading will flourish when they are given time and space to exercise and experiment their skills. As suggested by these authors (Alwasilah, 2002; Lengkanawati, 2004; Lamb, 2004; Marcellino, 2008; Rachmajanti, 2017), critical thinking remains intact as a curriculum document rather than as part of day-to-day teaching practices.

Related to the planning, monitoring and evaluation of feelings in reading, it was found that the majority of them were not able to implement critical thinking in reading due to their inability to plan, monitor and evaluate their feelings. Feelings of incompetence and the way they were raised might have negatively impacted their implementation of critical thinking in reading.

Although students believed that critical thinking was important in reading and acknowledged the importance of employing certain techniques in reading, they did not understand these strategies fully and therefore were not able to use effectively them when required in reading. They tended to use similar and familiar strategies to all reading texts and situations. 
Overall, the quantitative and qualitative data analyses suggest that most of the students were not yet able to consistently implement critical thinking in reading although there were indications of the planning, monitoring, and evaluation strategies being implemented sporadically. The findings were consistent with previous authors (see Alwasilah, 2002; Lengkanawati, 2004; Lamb, 2004; Marcellino, 2008; Rachmajanti, 2017), who argued that since an early age, most of the teaching inside Indonesian classrooms was centred on the teacher delivering a prescribed curriculum with little room for critical thinking to develop. The finding suggests the need for further and more practice of students' declarative, procedural and conditional knowledge of critical thinking in reading.

\section{CONCLUSION}

The investigation of Indonesian EFL learners' critical thinking in reading suggests that the majority of them had a sufficient understanding of critical thinking in reading at the conceptual level, i.e., they were able to mention some critical thinking strategies in reading. They also acknowledged the importance of critical thinking in reading. However, they need to develop a comprehensive understanding of the concept, that is, the declarative knowledge of critical thinking in reading. In addition, the students need to possess the procedural knowledge, i.e., knowing how to use the skills, and conditional knowledge, i.e, knowing when and why to use certain strategies as required by the passage. Overall, students indicated their understanding of and ability to use some critical thinking in reading, but to become critical, they need to be in a learning environment where their critical thinking could be intensively and regularly nurtured.

\section{REFERENCES}

Bailin, S., Roland, C., Coombs, J.R. \& Daniels, L.B. (1999). Conceptualising critical thinking. Curriculum Studies, 31(3), 285-302.

Brown, A. (1987). Metacognition, executive control, selfregulation and other more mysterious mechanisms. In F. E. Weinert \& R. H. Kluwe (Eds.), Metacognition, motivation and understanding (pp. 65-116). Hinsdale, NJ: Erlbaum.

Chamot, A. U., \& O'Malley, J. (1994). The CALLA handbook: Implementing cognitive academic language learning approach. Reading, MA: Addison-Wesley.

Chamot, A. U., Barnhardt, S., El-Dinary, P., \& Robbins, J. (1999). The learning strategies handbook. White Plains, NY: Addison Wesley Longman.
Cottrell, S. (2005). Critical thinking skills. Developing effective analysis and argument $\left(2^{\text {nd }} \mathrm{ed}\right)$. Hamsphire, NY: Palgrave McMillan.

Creswell, J. W. (2012). Qualitative inquiry \& research design: Choosing among five approaches (4th ed.). Thousand Oaks, CA: Sage.

Downing, D., Kwong, T., Chan, S.W., Lam, T.F., Downing, W.K. (2009). Problem-based learning and the development of metacognition. Higher Education, 57(5), 609-621. DOI: https://doi.org/10.1007/ s10734-008-9165-X

Fisher, R. (2008). Teaching thinking: Philosophical enquiry in the classroom (3rd ed.). London: Continuum.

Fisher, D. \& Frey. N. (2015). Contingency teaching during close reading. The Reading Teacher, 68(4).

Griffith, P. L., \& Ruan, J. (2005). What is metacognition and what should be its role in literacy instruction? In S. E. Israel, C. C. Block, K. L. Bauserman \& K. K. Welsch (Eds.), Metacognition in literacy learning: Theory, assessment, instruction and professional development (pp. 3-18). Mahwah, NJ: Lawrence Erlbaum.

Hove, G. (2011). Developing critical thinking skills in the high school English classroom. A Research Paper. Wisconsin: University of Wisconsin-Stout.

Ilyas, H.P. (2016). Infusing critical thinking into English course books. Journal of ELT Research, 1(1), 113134

Indah, R.N. \& Kusuma, A.W. (2016). Factors affecting the development of critical thinking of indonesian learners of English language. Journal Of Humanities And Social Science, 21(6), 86-94.

Indah, R.N. (2017). Critical thinking, writing performance and topic familiarity of Indonesian EFL learners. Journal of Language Teaching and Research, 8(2), 229-236. DOI: http://dx.doi.org/10.17507/ jltr.0802.04

Kuhn, D. (1999). A developmental model of critical thinking. Educational Researcher, 28(2), 16-25 and 46.

Lamb, M. (2004). 'It depends on the students themselves': Independent language learning at an Indonesian state school. Language, Culture and Curriculum, 17(3), 229-245.

Marcellino, M. (2008). English language teaching in Indonesia: A continuous challenge in education and cultural diversity. TEFLIN Journal, 19(1), 57-69.

Mbato, C.L. (2013). Facilitating EFL learners' self-regulation in reading: Implementing a metacognitive approach in a higher education context. Dissertation, Southern Cross University, Lismore, NSW, Australia.

Neuman, W. L. (2006). Research Methods:Quantitative and Qualitative Approaches. Boston, MA: Pearson Education.

Onwuegbuzie, A. J., Johnson, R. B., \& Collins, K. M. T. 
(2009). Call for mixed analysis: A philosophical framework for combining qualitative and quantitative approaches. International Journal of Mutliple Research Approaches, 2(2), 114-139.

Park, Y. (2011). Using news articles to build a critical literacy classroom in an EFLsetting. TESOL Journal, 2(1), 24-51.

Paul, R. (1990). Critical thinking. Rohnert Park, CA: Center for Critical Thinking and Moral Critique, Sonoma State University.

Paul, R. (2005), The state of critical thinking today. New Directions for Community Colleges, 27-38. DOI: 10.1002/cc.193.

Paul, R., \& Elder, L. (2008). The miniature guide to critical thinking: Concepts and tools. Retrieved on May 18, 2018 from www.criticalthinking.org.

Rachmajanti, S. (2017). Building cultural awareness and critical thinking skills through project-based task: a workshop for Indonesian context. The 4th International Conference on Language, Society and Culture in Asian Contexts, KnE Social Sciences, 498-504. DOI: 10.18502/kss.v1i3.772.

Stapleton, P. (2011). A survey of attitudes towards critical thinking among Hong Kong secondary school teachers: Implications for policy change. Thinking Skills and Creativity, 6(1), 14-23. DOI: 10.1016/j. tsc.2010.11.002.

Wallace, C. (2003). Critical reading in language education. London: Palgrave McMillan.

Wallace, M., \& Poulson, L. (2005). Critical reading for selfcritical writing. In A. Goodwyn \& A. Stables (Eds.), Learning to read critically in language and literacy (pp. 3-38). Newcastle: Sage Publications.

Walters, K.S. (1990). Critical thinking, rationality, and the vulcanisation of students. Journal of Higher Education, 61(4), 448-467.

Weinstein, C. E., Husman, J., \& Dierking, D. R. (2000). Self-regulation interventions with a focus on learning strategies. In M. Boekaerts, P. R. Pintrich \& M. Zeidner (Eds.), Handbook of self-regulation (pp. 728-744). San Diego, CA: Academic Press.

Yang, Y. C., Gamble, J. Hung, Y.W., \& Lin, T.Y. (2013). An online adaptive learning environment for criticalthinking-infused English literacy instruction. British Journal of Educational Technology, 45(4), 727-747. DOI:10.1111/bjet.12080

\section{APPENDIX}

The questionnaire on Critical Thinking in Reading (adopted and adapted from Cottrell, 2005, p. 13; Chamot \& O’Malley, 1994; Chamot; Barnhardt, El-Dinary, \& Robbins, 1999)

Statements pertaining to the use of planning, monitoring and evaluation of critical thinking strategies in reading

\begin{tabular}{|l|l|l|l|l|}
\hline No. & Statements & Diasgree & Undecided & Agree \\
\hline CT1 & I can critique the logic of the text & & & \\
\hline CT2 & I remain focused on the exact requirements of a reading activity & & & \\
\hline CT3 & I can analyse the structure of an argument & & & \\
\hline CT4 & $\begin{array}{l}\text { I can figure out the facts, experiences, data the author is using to support } \\
\text { her/his conclusions }\end{array}$ & & & \\
\hline CT5 & I recognize the signals used to indicate stages of an argument in the reading & & & \\
\hline CT6 & I can separate key points from other material & & & \\
\hline CT7 & I can find key problems (key question) in the reading & & & \\
\hline CT8 & I can identify unfair techniques used to persuade readers & & & \\
\hline CT9 & $\begin{array}{l}\text { I can figure out the main assumption(s) underlying the author's thinking } \\
\text { (that may be taken for granted) in the reading }\end{array}$ & & & \\
\hline CT10 & I can evaluate the evidence in the reading to support a point of view & & & \\
\hline CT11 & I pay attention to small details in the reading & & & \\
\hline CT12 & I can weigh up different points of view in the reading fairly & & \\
\hline CT13 & $\begin{array}{l}\text { I do research to find out more about something related to the reading to } \\
\text { strengthen my understanding. }\end{array}$ & & & \\
\hline
\end{tabular}




\begin{tabular}{|l|l|l|l|l|}
\hline CT14 & I can spot inconsistencies in an argument easily. & & & \\
\hline CT15 & I can identify the unclear arguments used in the reading. & & & \\
\hline CT16 & I can evaluate the sources of data used as references in the reading. & & & \\
\hline CT17 & $\begin{array}{l}\text { I can identify the key conclusions the author comes to and presents in the } \\
\text { article. }\end{array}$ & & & \\
\hline
\end{tabular}

Statements pertaining to the use of Planning, monitoring and evaluation of Feelings in reading.

\begin{tabular}{|l|l|l|l|l|}
\hline No. & Statement & Disagree & Undecided & Agree \\
\hline CT18 & $\begin{array}{l}\text { I feel comfortable in pointing out the weakness of an expert's work in } \\
\text { reading }\end{array}$ & & & \\
\hline CT19 & I can offer criticism to the reading without feeling bad & & & \\
\hline CT20 & I am aware of my current beliefs' prejudice on fair consideration of an issue & & & \\
\hline CT21 & I am patient in identifying the line of reasoning in an argument & & & \\
\hline CT22 & I am patient in going over the facts in order to reach an accurate view & & & \\
\hline CT23 & $\begin{array}{l}\text { I realise how my upbringing might prejudice fair consideration of an issue } \\
\text { in the reading }\end{array}$ & & & \\
\hline
\end{tabular}

